\title{
Hallucinations, prolonged QTc following fluoxetine overdose
}

\author{
Jemina Oremeyi Onimowo
}

\begin{abstract}
Introduction: Fluoxetine is a selective serotonin reuptake inhibitor (SSRI) used in the treatment of depressive disorders. Cardiotoxicity and neurotoxicity have rarely been attributed to the use of fluoxetine. Several clinical studies showed that fluoxetine is less likely to cause significant cardiovascular toxicity even in overdose. Other studies showed that ingestions of $40-800 \mathrm{mg}$ fluoxetine have generally produced minimal toxicity in adults. Of note, fluoxetine and ibuprofen increase toxicity of each other by pharmacodynamic synergism. Case Report: This is the case of widened QRS duration in a 21-year-old female with background depression. She had taken a mixed overdose of fluoxetine (600 mg), omeprazole (600 mg), ibuprofen (1200 mg), metronidazole (unclear amount). On admission she was hallucinating, profoundly agitated, tachycardic with a heart rate of 128 bpm, new broadening in QRS complex to 134 ms on electrocardiography, corrected QT (QTe) was $616 \mathrm{~ms}$. Following discussion with TOXBASE, she was given $2 \mathrm{~g}$ magnesium sulfate, 1.4\% sodium bicarbonate, admitted to high dependency unit for cardiac monitoring. She also needed sedation. Conclusion: This case is interesting from the point of view of broad
\end{abstract}

Jemina Oremeyi Onimowo

Affiliation: Core Trainee year 3, Acute Care Common StemAcute Medicine) North Devon District Hospital, Barnstaple, England.

Corresponding Author: Dr. Jemina Oremeyi Onimowo, Core Trainee year 3, Acute Care Common Stem- Acute Medicine) North Devon District Hospital, Barnstaple, England; Email: jemina.onimowo@nhs.net

Received: 20 November 2017

Accepted: 29 November 2017

Published: 01 February 2018 complex tachycardia that could result in cardiac arrest due to a prolonged QTe of $616 \mathrm{~ms}$, as well as the visual and auditory hallucinations the patient had. It also raised the question of possibility of pharmacodynamic drug-drug interaction in which ibuprofen could have via synergism, potentiated the cardiotoxic effects of an otherwise generally safe SSRI; fluoxetine.

Keywords: Complex drug-drug interactions, ECG abnormalities, Fluoxetine overdose, Hallucinations, Prolonged QTC, SSRI overdose

\section{How to cite this article}

Onimowo JO. Hallucinations, prolonged QTc following fluoxetine overdose. Int J Case Rep Images 2018;9:100884Z01JO2018.

Article ID: 100884Z01JO2018

$$
* * * * * * * * *
$$

doi: 10.5348/100884Z01JO2018CR

\section{INTRODUCTION}

Fluoxetine has been approved by the Food and Drug Administration (FDA) for the treatment of depression, obsessive compulsive disorder, premenstrual dysphoric disorder and other mood disorders $[1,2]$. The mechanism of action is by blocking serotonin reuptake and increasing serotonin stimulation of somatodendritic 5 - $\mathrm{HT} 1 \mathrm{~A}$ and terminal autoreceptors [3, 4]. Fluoxetine is considered minimally toxic in overdose especially when compared to tricyclic antidepressants [4]. In spite of this, there have been rare descriptions of severe complications and even fatalities with doses in excess of 75 times prescription dose or as a mixed overdose $[4,5]$. 


\section{EDORIUM Journals}

A case of hallucinations and cardiac conduction abnormalities in a young lady resulting from fluoxetine over dose is described here. Researching into the side effect and pharmacodynamic profile of fluoxetine, ibuprofen, metronidazole, mebeverine and omeprazole which were co-ingested at the time, show that symptoms described in this case, have been documented as possible but very rare adverse effect in the high dose of fluoxetine [2]. There is the possibility that several complex drug-drug interactions could have contributed to the potentiation of its toxicity profile $[5,6]$. Fluoxetine is a potent enzyme inhibitor, and significantly affects CYP2D6, CYP3A4 and CYP2C19 activity in vitro [6]. These enzymes are required for the metabolism of most drugs including ibuprofen, omeprazole and fluoxetine itself. An inhibitory effect will account for the persistence of these medications in the system. Ibuprofen is also capable of inhibiting CYP2C9/10 enzyme activity thereby further potentiating fluoxetine's activity as well $[6,7]$.

\section{CASE REPORT}

A 21-year-old female was presented to emergency department (resuscitation room) with background depression and asthma. Brought in by ambulance, she had presented with hallucinations and profound agitation following intentional mixed overdose of 600 $\mathrm{mg}$ fluoxetine, $600 \mathrm{mg}$ omeprazole and unknown quantities of metronidazole, mebeverine and ibuprofen. There was no history of psychosis or congenital cardiac abnormalities. She had no known drug allergies.

On examination airway was self-maintained and patent, with spontaneous ventilation saturating $100 \%$ on room air, tachypnoeic with a respiratory rate of 20 cycles per minute. Peripheries were warm, well perfused and capillary refill time was less than two seconds with a heart rate of $135 \mathrm{bpm}$, blood pressure 132/48 $\mathrm{mmHg}$ and 12-lead ECG (find attached) showed tachycardia, prolonged QTc at $616 \mathrm{~ms}$ and wide QRS complex of 134 $\mathrm{ms}$. She was confused and was having visual and auditory hallucinations with a GCS of 14/15. Temperature was $36.5^{\circ} \mathrm{C}$ and blood sugar $4.9 \mathrm{mmol} / \mathrm{L}$. There was no evidence of muscle rigidity or hyperreflexia and nothing of significance was found on exposure.

Blood tests (laboratory and bedside venous blood samples (Table 1 and Table 2 ) where sent off and results did not show any significant abnormality. 12-lead electrocardiograms (Figures 1-3) were done and she was subsequently placed on cardiac monitoring.

TOXBASE was contacted via telephone and $2 \mathrm{~g}$ magnesium sulphate in view of the significant QTc of $616 \mathrm{~ms}$ and polymorphic ventricular tachycardia of 135 $\mathrm{bpm}, 500 \mathrm{ml}$ of $1.4 \%$ sodium bicarbonate for the QRS prolongation at $134 \mathrm{~ms}$ were given as advised.

After she had been stabilized in the emergency department, she was transferred to the high dependency unit for cardiac monitoring and close observation. Thirty-
Table 1: Venous blood gas results and normal ranges

\begin{tabular}{llc} 
& \multicolumn{1}{c}{ Patient } & Normal range \\
$\mathrm{pH}$ & 7.421 & $7.350-7.450$ \\
$\mathrm{PCO} 2$ & $5.44 \mathrm{kPa}$ & $<6 \mathrm{kPa}$ \\
$\mathrm{PO} 2$ & $4.99 \mathrm{kPa}$ & $>8 \mathrm{kPa}$ \\
$\mathrm{HCO}{ }^{-}$ & $25.3 \mathrm{mmol} / \mathrm{L}$ & $22-29$ \\
Base & $1.0 \mathrm{mmol} / \mathrm{L}$ & $-2.0-2.0$ \\
$\mathrm{Na}$ & $145 \mathrm{mmol} / \mathrm{L}$ & $133-146$ \\
$\mathrm{~K}$ & $3.4 \mathrm{mmol} / \mathrm{L}$ & $3.5-5.3$ \\
Ca & $1.15 \mathrm{mmol} / \mathrm{L}$ & $1.13-1.32$ \\
Glucose & $4.5 \mathrm{mmol} / \mathrm{L}$ & $3.8-11$ \\
Lactate & $2.1 \mathrm{mmol} / \mathrm{L}$ & $0.6-2.5$ \\
Haemoglobin & $157 \mathrm{~g} / \mathrm{L}$ & $115-170$ \\
\hline
\end{tabular}

Table 2: Laboratory biochemical results and normal ranges

\begin{tabular}{llc} 
& \multicolumn{1}{c}{ Patient } & Normal range \\
Sodium & $141 \mathrm{mmol} / \mathrm{L}$ & $133-146$ \\
Potassium & $3.8 \mathrm{mmol} / \mathrm{L}$ & $3.5-5.3$ \\
Urea & $2.8 \mathrm{mmol} / \mathrm{L}$ & $2.5-6.2$ \\
Creatinine & $58 \mathrm{umol} / \mathrm{L}$ & $95-108$ \\
CCalcium & $2.28 \mathrm{mmol} / \mathrm{L}$ & $2.2-2.6$ \\
Phosphate & $1.2 \mathrm{mmol} / \mathrm{L}$ & $0.8-1.5$ \\
Magnesium & $1.07 \mathrm{mmol} / \mathrm{L}$ & $0.7-1.0$ \\
Paracetamol & $<5 \mathrm{mg} / \mathrm{L}$ & $<5$ \\
eGFR & $>90$ & $>90$ \\
\hline
\end{tabular}

Liver function tests within normal range

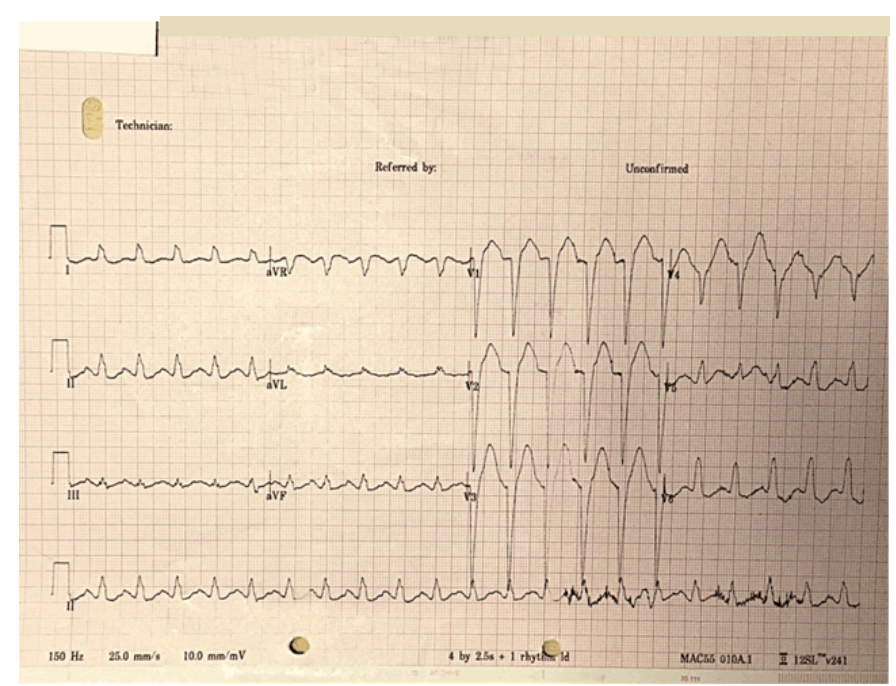

Figure 1: Electrocardiography post overdose showing prolongation of Qtc to $616 \mathrm{~ms}$. 


\section{EDORIUM Journals}

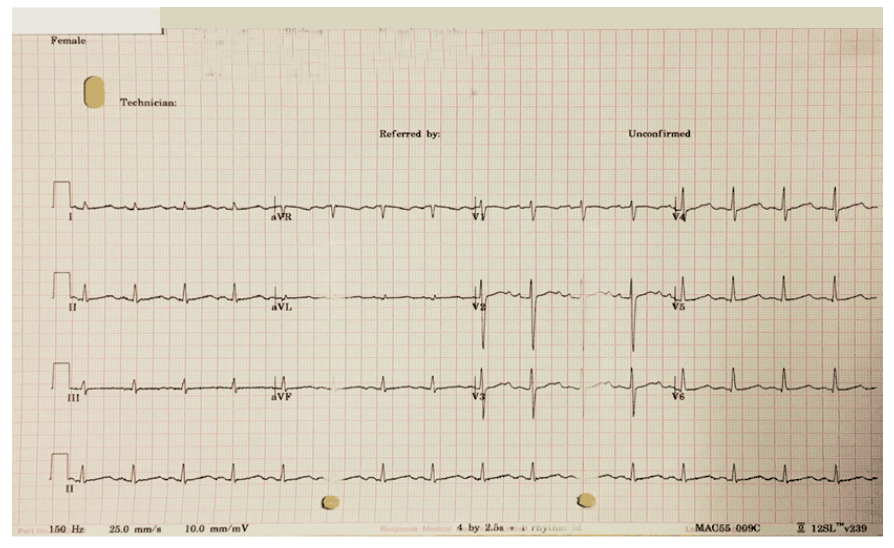

Figure 2: Electrocardiography post magnesium and sodium bicarbonate showing improvement of QTc and QRS complexes.

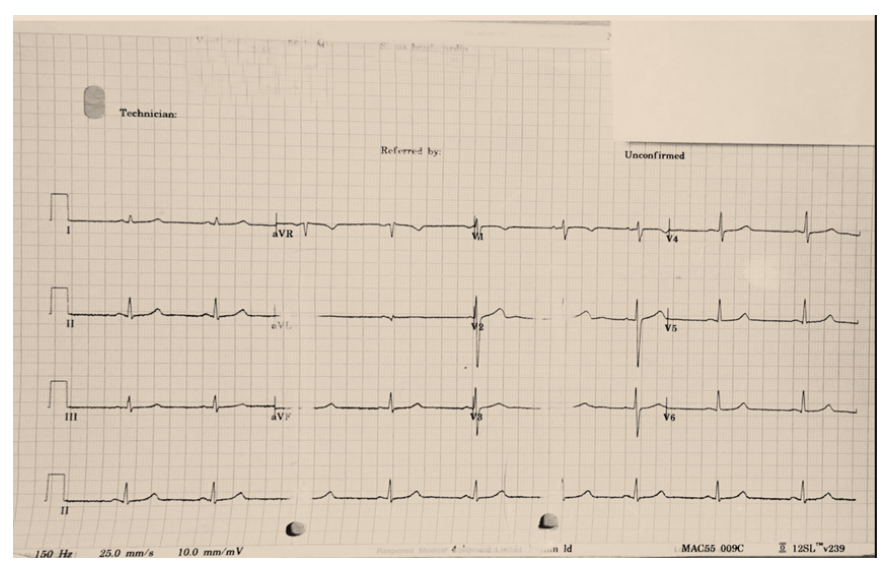

Figure 3: Electrocardiography 12 hours post intervention showing resolution of conduction abnormality.

six hours following this ordeal, both cardiac abnormalities and hallucinations had completely resolved. She was declared medically fit and subsequently reviewed and discharged by the mental health team, with outpatient follow-up.

\section{DISCUSSION}

Searching through the databases, there is noticeably limited information available on the neurotoxic and cardiotoxic effects of fluoxetine. Those available do not associate it with any sinister effects even in overdose and in fact portray it as considerably benign $[1,10,11]$. None of the other medications co-ingested (ibuprofen, omeprazole, mebeverine, and metronidazole) could completely explain the conduction abnormalities, severe agitation as well as hallucinations in this case $[1$, $2,8]$. The side effects of ibuprofen rash, renal damage, headaches and hearing disturbances and increased risk of thrombotic events. Mebeverine was associated with rash, angioedema and allergic reactions. Metronidazole could cause peripheral neuropathy, pancreatitis and seizures. Apart from ibuprofen common adverse effect profile did not include any form of cardiotoxicity [7, 8]. With omeprazole nausea, vomiting abdominal pain were features of its common side effects and in chronic use could result in dyselectrolytemia of which hypomagnesemia could potentially be of cardiac significance but is invariably quite rare [8].

On reviewing the report on 234 cases of fluoxetine overdose; tachycardia, drowsiness, tremor, vomiting and nausea were the most common side effects seen [9]. In a separate review of fluoxetine intentional overdose, by Pope and Zaraa in 2016, none of the patients had any cardiac conduction abnormality on ECG [10]. A study of the toxicity profile of five SSRIs, noted that citalopram was responsible for over 68\% of prolonged QTc and the conclusion was that the rest of the SSRIs, fluoxetine inclusive remained relatively safe in overdose [11].

In our index case, we noted that within six hours of ingestion of $600 \mathrm{mg}$ of fluoxetine (on presentation) she had visual hallucinations and remained highly agitated with a GCS of $14 / 15$. She was not known to have any previous episodes of delusions or hallucinations.

Conduction abnormalities related to fluoxetine, result from prolongation of repolarization the resulting long QT syndrome. This is brought about by blockade of hERG $\mathrm{K}+$ channel as well as disruption of protein channel trafficking [12].

Unlike in this case being discussed, reports of CNS and cardiac toxicity occurring together following fluoxetine overdose have rarely ever been described in literature. There is evidence in support of fluoxetine neurotoxicity with resultant generalized tonic clonic seizure and in another study the patient developed acute psychosis [13, 14].

The dramatic prolongation of her QTc and the clinical significance of this potentially leading to torsade de Pointes in this patient begs the question as to whether or not fluoxetine in itself is capable of this degree of cardiotoxicity, or whether there was some additive effect by some of the other medications she had ingested at the time. Of all the other drugs co ingested, ibuprofen has a cardiac toxicity profile in its own right. It is a nonsteroidal anti-inflammatory drug mediating its analgesic properties by inhibition of cyclooxygenase $2[7,8,16]$ The results of an observational study by Pratt et al., showed that ingestion ibuprofen increased the chances of developing cardiac arrhythmias [15]. Multiple cases of ibuprofen overdose have reported narrow complex tachycardias $[16,17]$, and although in this report symptoms were of a polymorphic ventricular tachycardia, it is plausible that this nonsteroidal anti-inflammatory drugs (NSAIDs) characteristic of causing cardiac abnormalities could have potentiated the symptoms of adverse cardiotoxicity described here.

Investigating the drug-drug interactions show that fluoxetine and ibuprofen exhibit some pharmacosynergism of which both potentiate the activity of the other. Several studies denote that in the presence of 


\section{EDORIUM Journals}

www.ijcasereportsandimages.com

fluoxetine, NSAIDS are likely to increase the risk of upper gastrointestinal tract bleeding. But there is little documented research on ibuprofen in turn potentiating the toxic profile of Fluoxetine.

\section{CONCLUSION}

This is a case of hallucinations, widened QRS and prolongation of QTc in a young female following a mixed drug over dose, primarily of fluoxetine. There is evidence of complex drug-drug interaction between the commonly prescribed antidepressant; fluoxetine and the easily available over the counter NSAID; ibuprofen which could be deleterious in situations of overdose and requires further research. Review of the ease of their accessibility and monitoring in combined use is of grave importance.

\section{REFERENCES}

1. Wong DT, Bymaster FP, Engleman EA. Prozac (fluoxetine, Lilly 110140), the first selective serotonin uptake inhibitor and an antidepressant drug: Twenty years since its first publication. Life Sci 1995;57(5):411-41.

2. https://www.fda.gov/ohrms/dockets/ac/o4/ briefing/2004-4065b1-35-PROZAC-CLASSLABELING.htm

3. Descarries L, Riad M. Effects of the antidepressant fluoxetine on the subcellular localization of 5 - $\mathrm{HT} 1 \mathrm{~A}$ receptors and SERT. Philos Trans R Soc Lond B Biol Sci 2012 Sep 5;367(1601):2416-25.

4. Suchard JR. Fluoxetine overdose-induced seizure. West J Emerg Med 2008 Aug;9(3):154-6.

5. Barbey JT, Roose SP. SSRI safety in overdose. J Clin Psychiatry 1998;59 Suppl 15:42-8.

6. Sager JE, Lutz JD, Foti RS, Davis C, Kunze KL, Isoherranen N. Fluoxetine- and norfluoxetinemediated complex drug-drug interactions: In vitro to in vivo correlation of effects on CYP2D6, CYP2C19, and CYP3A4. Clin Pharmacol Ther 2014 Jun;95(6):653-62.

7. Drug interaction checker. [Available at: https://www. rxlist.com/drug-interaction-checker.htm]

8. British national formulary/NICE. [Available at: https://www.evidence.nhs.uk/Search?q=British+nat ional+formulary+NICE]

9. Borys DJ, Setzer SC, Ling LJ, Reisdorf JJ, Day LC, Krenzelok EP. Acute fluoxetine overdose: A report of 234 cases. Am J Emerg Med 1992 Mar;10(2):115-20.

10. Pope S, Zaraa SG. Serum fluoxetine and norfluoxetine levels support the safety of fluoxetine in overdose. Ann Gen Psychiatry 2016 Nov 9;15:30.

11. Isbister GK, Bowe SJ, Dawson A, Whyte IM. Relative toxicity of selective serotonin reuptake inhibitors (SSRIs) in overdose. J Toxicol Clin Toxicol 2004;42(3):277-85.

12. Rajamani S, Eckhardt LL, Valdivia CR, et al. Druginduced long QT syndrome: hERG K+ channel block and disruption of protein trafficking by fluoxetine and norfluoxetine. Br J Pharmacol 2006 Nov;149(5):4819.

13. Graudins A, Vossler C, Wang R. Fluoxetine-induced cardiotoxicity with response to bicarbonate therapy. Am J Emerg Med 1997 Sep;15(5):501-3.

14. Karlsson H, Hietala J, Saarijärvi S. Acute paranoidhallucinatory psychosis after an overdose of fluoxetine and Enalapril: A case report. Nordic Journal of Psychiatry 1998;52(2).

15. Pratt CM, Hertz RP, Ellis BE, Crowell SP, Louv W, Moyé L. Risk of developing life-threatening ventricular arrhythmia associated with tefenadine in comparison with over-the-counter antihistamines, ibuprofen and clemastine. Am J Cardiol 1994 Feb 15;73(5):346-52.

16. Fil L, Gupta A, Majlesi N. Atrial fibrillation in the setting of an acute single ingestion of ibuprofen. Clinical Toxicology 2014;52(7):741.

17. Levine B, Jones R, Smith ML, Gudewicz TM, Peterson B. A multiple drug intoxication involving cyclobenzaprine and ibuprofen. Am J Forensic Med Pathol 1993 Sep;14(3):246-8.

$$
* * * * * * * * *
$$

\section{Acknowledgements}

Thanks to Dr Nicholas Love (consultant intensive care and anesthetics) for his support through the writing of this report.

\section{Author Contributions}

Jemina Oremeyi Onimowo - Substantial contributions to conception and design, Drafting the article, Final approval of the version to be published

\section{Guarantor of Submission}

The corresponding author is the guarantor of submission.

\section{Source of Support}

None

\section{Consent Statement}

Written informed consent was obtained from the patient for publication of this case report.

\section{Conflict of Interest}

Author declares no conflict of interest.

\section{Copyright}

(C) 2018 Jemina Oremeyi Onimowo. This article is distributed under the terms of Creative Commons Attribution License which permits unrestricted use, distribution and reproduction in any medium provided the original author(s) and original publisher are properly credited. Please see the copyright policy on the journal website for more information. 
Access full text article on other devices

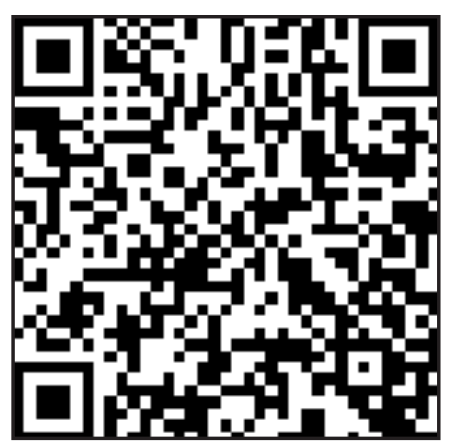

Access PDF of article on other devices

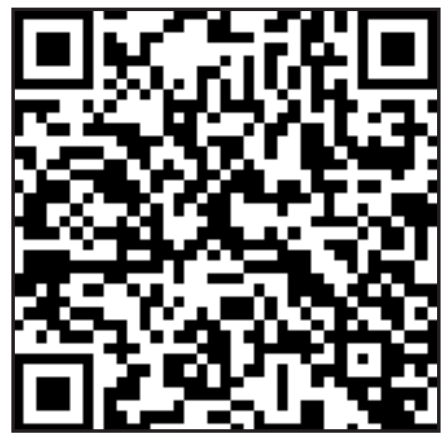

